\title{
A MODELAGEM MATEMÁTICA PARA O ENSINO DA GEOMETRIA - RELAÇÃO DE EULER
}

\author{
PEREIRA, LedinaLentz ${ }^{1}$ \\ AGUIAR, Luciane Oliveira de ${ }^{2}$ \\ SELAU, Juliana ${ }^{3}$ \\ CATARINA, Alyne ${ }^{4}$
}

RESUMO: Apresenta-se neste trabalho o resultado de uma das experiências desenvolvidas pelos acadêmicos do projeto Institucional do Programa de Bolsas de Iniciação a Docência PIBID/UNESC/CAPES ${ }^{5}$, especificamente do subprojeto da área de Matemática. Que foi a elaboração e aplicação de uma proposta de ensino de geometria espacial, fundamentada nos estudos de duas dissertações de mestrado -MIALICH, (2012) e ANDRADE,(2014) e a Modelagem Matemática-MM proposta por ALMEIDA,(2012). A proposta foi elaborada e aplicada com alunos do $8^{\circ}$ ano de uma escola de Educação Básica no município de Criciúma/SC. Os resultados apresentados em todo o processo foram considerados positivos em relação à experiência desenvolvida pelos acadêmicos bolsistas-AB do subprojeto PIBID/Matemática/UNESC e, segundo os $A B$, surpreendente na aplicação da proposta.

Palavras chave: Modelagem Matemática; proposição de ensino; Geometria espacial; Formação docente.

\section{ABSTRACT}

The purpose of this paper is to present the results of the experiences developed by the scholars of the Institutional Project of the Initiation to Teaching Scholarship Program - PIBID / UNESC / CAPES, specifically the Mathematics subproject. That was the development and implementation of an educational of spatial geometry, based on the studies of two master's dissertations- MIALICH, (2012) and ANDRADE, (2014) and the MM-Mathematical Modeling proposed by ALMEIDA, (2012). The proposal was elaborated and applied with eighth grade students from a Primary School in the city of Criciúma / SC. The results for the entire process were considered positive in relation to the experience developed by academics scholars-AB of the subproject PIBID / Mathematics / UNESC and, according to the $A B$, surprising in the application of the proposal.

Keywords: Mathematical Modeling; Teaching proposition; Spatial geometry; Teacher training.

\section{1 -Introdução/Fundamentação Teórica}

O interesse pela atividade de ensino fundamentada na MM como estratégia para as aulas de Matemática, trabalhando conceitos da geometria

\footnotetext{
${ }^{1}$ Universidade do Extremo Sul Catarinense - UNESC/SC - $\underline{\text { llp@unesc.net }}$

${ }^{2}$ UNESC/SC - ciane 7@hotmail.com

${ }^{3}$ UNESC/SC - juh selau@hotmail.com

${ }^{4}$ UNESC/SC - alynecatarina@hotmail.com

${ }^{5}$ Coordenação de Aperfeiçoamento de Nível Superior
} 


\section{CRIAR EDUCAČ̃̃̃O}

Revista do Programa de Pós-Graduação em Educação - UNESC

espacial, para alunos da Educação Básica (EB), justifica-se pela busca de alternativas que promovam a melhoria da qualidade de ensino/aprendizagem destes temas, como também numa formação docente de qualidade, pois paraTardif (2011), os saberes experienciais dos professores são resultados de um processo de construção individual, mas, ao mesmo tempo, compartilhados e legitimados por meio de processos de socialização de saberes. E, por consequência, oportunizar também aos $A B$ do PIBID/UNESC/CAPES e aos professores de Matemática da EB das escolas públicas o fortalecimento de uma reflexão crítica da prática docente como formação e aprendizagem, na perspectiva do docente pesquisador.

Por um lado, considera-se que a geometria possibilita desenvolver 0 pensamento crítico dos alunos, podendo representar de forma organizada o mundo em que vivem e de outro contribuir para formação dos $A B$ do PIBID/UNESC, no sentido de incentivá-los na elaboração de uma possibilidade didática de ensino e aprendizagem da geometria espacial e a sua aplicação em sala de aula. E, como a MM, tem também como objetivo, proporcionar ao aluno oportunidades de estudar situações problemas de sua realidade, com a possibilidade de solucioná-las com uso da matemática e

"se trabalhada de forma criativa, motivadora e eficaz, a Modelagem Matemática pode trazer benefícios, como por exemplo, motivação, facilidade na aprendizagem, desenvolvimento do raciocínio e desenvolvimento do aluno como cidadão crítico, dentre outros" (MACEDO, 2013, p. 18),

demonstrarao aluno como a matemática pode ser útil em sua vida fora do ambiente escolar e também como ela está relacionada às demais áreas do conhecimento.Também, segundo Almeida e Brito (2005), as atividades de MM temse mostrado bastante adequada na prática de sala de aula, pois a medida que o aluno vai realizando as atividades nos diferentes momentos e de acordo com a sequência apresentada, a sua compreensão em relação aos conceitos matemáticos envolvidosna resolução do problema em estudo e da reflexão sobre os resultados encontrados vão se sistematizando para ele.

É neste contexto que, o objetivo deste trabalho foialém de contribuir para formação docente dos $A B$ com a elaboração de uma proposta de ensino fundamentada numa tendência em Educação Matemática que é a $M M$ de 


\section{CRIAR EDUCAČ̃̃̃O}

Revista do Programa de Pós-Graduação em Educação - UNESC

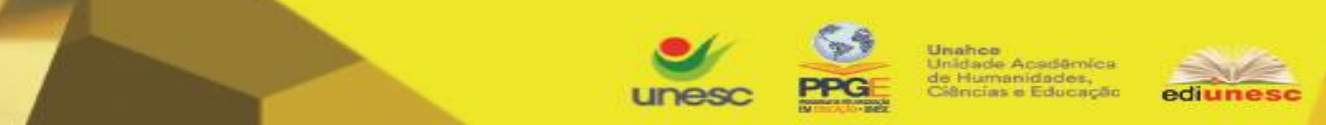

hipóteses e de se definir as variáveis necessárias para resolução do problema.

c) resolução - etapa que pode gerar muitas discussões nos grupos, precisando em alguns casos da intervenção doprofessor.Desenvolve-se, com a intervenção intencional do professor, que sugereà resolução de atividades que conduzem os alunos a construção do modelo matemático ${ }^{6}$, que resolva 0 problema. Momento que, discuti-se a questão das variáveis e, dependendo do problema, as suas representações no plano cartesiano. Na construção do modelo, se trabalha os conceitos matemáticos envolvidos na solução do problema proposto. Depois de concluído o modelo matemático,a proposta da atividade de MM não termina com a sua construção, ainda precisa-se verificar se ele resolve o problema proposto. E é esta a última e também importante etapa da proposta de MM.

d) Interpretação e validação dos resultados-com uso do modelo matemático elaborado na etapa anterior, verifica-sese a relação confere com os dados apresentados ou coletadosna apresentação do problema. Em caso positivo, o modelo estará pronto, mas caso contrário, volta-se a discussão sobre os conceitos matemáticos envolvidos e elabora-se um novo modelo.

\section{A proposição didática elaborada e aplicada neste trabalho se}

fundamenta nestas etapas da de Almeida et al., (2012), fundamentando-se também nas duas proposições a seguir:

\section{2 - Proposição de Mialich, (2013)}

A proposição, cujo tema central são os Poliedros e o Teorema de Euler como sugere o titulo da dissertação - faz sucinta análise da definição de Poliedros, com considerações históricas a respeito deles e do Teorema de Euler. Apresentando

\footnotetext{
${ }^{6}$ Modelo Matemático - fórmula matemática ou relação matemática que resolve o problema proposto.
} 


\section{CRIAR EDUCAČ̃̃̃O}

Revista do Programa de Pós-Graduação em Educação - UNESC

duas versões/demonstrações deste teorema, a primeira para poliedros convexos, e a segunda, conhecida como de Teorema de Euler segundo Cauchy (que engloba certos poliedros não convexos, que são homeomorfos à esfera).

Como consequência do Teorema de Euler, a demonstração do teorema da existência de cinco poliedros regulares, conhecidos comoPoliedros de Platão são apresentados no trabalho de Mialich, (2013). O trabalho analisa também 0 conteúdo/ensino de Poliedros em certosdocumentos oficiais ( $\mathrm{PCN}^{7}$, Currículo do Estado de São Paulo, Matrizes do SARESP ${ }^{8}$ eENEM $^{9}$ ). E conclui com uma proposição didática, que sugere o desenvolvimento deatividades que exploram os conceitos que envolvem os poliedros, oTeorema de Euler, como também área, volume e planificação deles. Apresenta análisee resolução de algumas questões do SARESP e ENEM (relativas a tais conteúdos), com uso do software matemático Poly, como ferramenta para uma aprendizagem mais significativa para os alunos. Conclui apresentando um parecer acerca de como estes conteúdos são apresentados em certos documentos oficiais.

Para adaptar, as etapas da proposição didática de MM de Almeida et al., (2012), este trabalho se fundamentou nos conceitos, teoremas e atividades propostas e apresentadas na proposição para o ensino da geometriade Mialich, (2013).

\section{3-Proposição de ANDRADE, (2014)}

Nessa proposição é apresentada uma sequência didática para o ensino de Geometria Espacial -com duas sugestões de aula: Relação de Euler e diagonal doparalelepípedo e do cubo. Com base na Neurociência e nos níveis deaprendizagem de Van Hiele, utiliza palitos de dente e jujubas(balas de goma) na construção dos sólidos de Platão, com o objetivo de ampliar a visão espacial dos alunos e de contribuir para a qualidade do ensino e da aprendizagem deste conteúdo no Ensino Médio.

\footnotetext{
${ }^{7}$ Parâmetros Curriculares Nacionais

${ }^{8}$ Secretaria da Educação do Estado de São Paulo

${ }^{9}$ Exame Nacional do Ensino Médio
} 


\section{CRIAR EDUCAČ̃̃̃O}

Revista do Programa de Pós-Graduação em Educação - UNESC

É uma poropsição didática que teve como base as Teorias de Van Hiele e Guitiérres, voltadas para o aprendizado de geometria espacial. Hiele e Gutièrrez formularam teorias que identificam fases do aprendizado em Geometria, sendo que o primeiro na área plana e o outro na espacial. E a técnica das jujubas consiste na construção de esqueletos de poliedros de Platão, de modo que as jujubas representam os vértices, e os palitos, as arestas.

Desta proposição didática este trabalho utilizou -além das construções dos poliedros de Platão a partir de suas planificações - a sugestão do uso de palitos de dente e das jujubas na construção dos poliedros de Platão.

\section{Metodologia}

Nas experiências relatadas na literatura é possível observar que a MM pode ser uma das estratégias de ensino que motiva o aluno a se interessar pelo estudo da Matemática, uma vez que nela o mesmo é desafiado a resolver problemas do dia a dia. Deste modo, o aluno é estimulado a participar, sendo co-responsável pela construção do seu conhecimento. Também, é uma atividade que possibilita a interação social entre os participantes da $\mathrm{MM}$, promovendo a internalização de instrumentos e signos, a ressignificação e aprendizagem de estratégias e conceitos científicos.

Diante disto, este trabalho tevecomo objetivo elaborar e aplicar uma proposição didática, que possibilitou deduzir/validar o modelo matemático daRelação de Euler- Poicaré - REP, comotambém contribuir para formação docente dos $A B$ do $\mathrm{PIBID/Matemática/UNESC.} \mathrm{E} \mathrm{neste} \mathrm{trabalho} \mathrm{os} \mathrm{ABalém} \mathrm{de} \mathrm{desenvolverem} \mathrm{conceitos}$ da geometria previstos nos documentos oficiais que norteiam o currículo das escolas, puderam aprenderde forma colaborativa e compartilhada uma das tendências em Educação Matemática, queé a MM. Para isto, foram desenvolvidasatividades de $\mathrm{MM}$ para o ensino e aprendizagem da geometria espacial para alunos do $8^{\circ}$ ano de uma escola no município de Criciúma/SC, em outubro/2015.

Criar Educação, Criciúma, v. 6, ำ1, janeiro/junho 2017.- PPGE - UNESC 


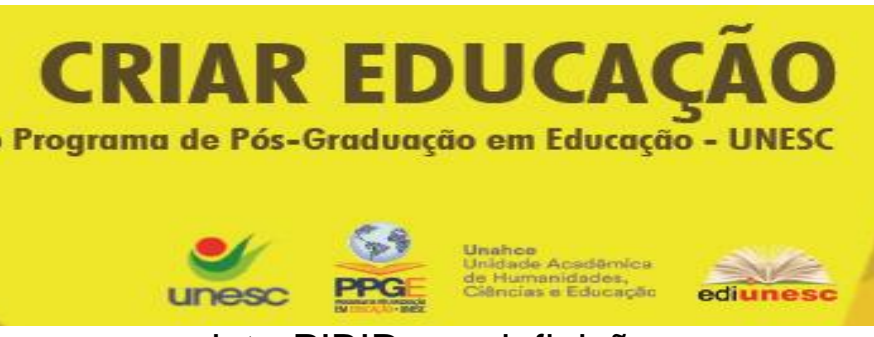

No início da atividade de MM apresentou-se o projeto PIBID e a definição da MM com enfoquena principal bibliografia sugerida por Almeida, et al.(2012), os alunos do $8^{\circ}$ ano em grupos de três e auxiliados pelos $A B$, construíram os sólidos com a técnica das jujubas de Andrade, (2014) e terminaram as atividades com validação do modelo matemático da REP.

\section{Resultados e Discussão}

No início da atividade, com os alunos divididos em grupos, apresentou-se - PIBID e a definição da MM com enfoque na bibliografia estudada. Após,foi desenvolvida a sequência didáticasugerida por Almeida, et al.(2012), com o objetivo de deduzir/validar o modelo matemático da REP.

$\mathrm{Na}$ etapa inicial da proposta de $\mathrm{MM}$, ainteiração, apresentou-se aproblemática: entender a validade da Relação de Euler na geometria espacial; Promoveu-se a interação dos conceitos referentes à geometria espacial com questionamentos como: quem foi Euler?; O que são poliedros? Classificação (Poliedros convexos e côncavos); Elementos de um Poliedro e a classificação dos poliedros convexos. Segundo a acadêmica bolsista A, o tema "foi de fácil entendimento e despertou muito o interesse dos alunos".

$\mathrm{Na}$ sequência,etapa daMatematização - com objetivo de transformar a linguagem natural para a da matemática e definir a variáveis envolvidas, foram propostas as primeirasatividades:complete atabela indicando o número de faces $F, 0$ de vértices $\mathrm{V}$ e $\mathrm{O}$ de arestas $\mathrm{A}$ de cada poliedro convexo indicado.Nela eram apresentados os poliedros de Platão planificados: tetraedro, hexaedro, octaedro, dodecaedro e o icosaedro.Segundo aacadêmica bolsista A, (2015) "foi visível o interesse da maior parte da turma e a dificuldade de alguns alunos. Cada grupo montou em média 5(cinco) sólidos a partir das planificações".Após, entregou-se aos alunos os kits com palitos e jujubas envoltas em papel filme (higienizadas anteriormente pelas $A B$ ), e a partir deste momento os grupos montaram também os sólidos de Platão com jujubas e palito de dente. 


\section{CRIAR EDUCAÇÃO}

Revista do Programa de Pós-Graduação em Educação - UNESC

Momento da próxima etapa, a resolução, que tem por objetivo a construção do modelo matemático, que no caso é chegar ao que representa a relação de Euler.Então, a partir dos sólidos construídos,foi proposta mais uma atividade: reconhecer e nomear os poliedros $(P)$ de Platão; identificar a quantidade de vértices $(\mathrm{V})$, faces $(\mathrm{F})$ e arestas $(\mathrm{A})$ nos mesmos. Os alunos preencheram a tabela abaixo.

Elementos de Platão

$$
\text { Poliedro (P) Vértices (V) } \quad \text { Arestas (A) } \quad \text { Faces (F) }
$$

dos Poliedros

Fonte: adaptado de Andrade, (2014)

Depois dos alunos preencherem as tabelas, os $A B$, seguindo as sugestões de Andrade, (2014), fizeram os seguintes questionamentos: será que os poliedros de Platão possuem características próprias? Vamos descobri-las? O objetivo era que eles visualizassem o que de comum existia em cada sólido, assim os alunos concluíram que todos os sólidos de Platão possuem o número de arestas maior que o de vértices e faces.

Para intencionalmente possibilitaraos alunos à construção do modelo de Euler, foi formulada a seguinte atividade: Cada grupo com uso das operações de adição e subtração, elaborar uma equação que seja comum a todos os sólidos construídos. Etapa que como o esperado gerou muitas discussões nos grupos, precisando - em muitos momentos - da intervenção/mediação dos AB.Depois, pediuse que descobrissem uma relação que fosse comum aos sólidos de Platão, com a possibilidade de adicionar ou subtrair números nesta mesma relação. Os objetivos desta etapa foram atingidos, pois os alunos formularam a relação de Euler. Os 


\section{CRIAR EDUCAČ̃̃̃O}

Revista do Programa de Pós-Graduação em Educação - UNESC

alunos conseguiram estabelecer a relação entre a quantidade de vértices, arestas e faces dos poliedros de Platão, como pro exemplo no Tetraedro T tem-se

$$
X(T)=V-A+F=2
$$

E com a elaboração do modelo matemático para solução da problemática, passouse para última etapa da MM, a interpretação e validação do modelo construído. Para isto, apresentaram-se sólidos não que não eram de Platão, mas que a relação era também verdadeira, fazendo os seguintes questionamentos: "será que a relação encontrada é suficiente para identificar os poliedros de Platão? Ou melhor, será que ela só é verdadeira nos poliedros platônicos?" Desta forma, um estudo maior teve que ser feito. Então, finalizou-se a atividade de MM com a apresentação da REP, referente à característica homeomorfa dos sólidos de Platão à esfera, fazendo uma explanação sobre topologia e possibilitando a validação do modelo, pois - por exemplo - para o tetraedro $\mathrm{T}$ tem-se (1) e $\mathrm{T}$ é homeomorfo a esfera, o que não aconteceu com o novo sólido apresentado. Validando assim o modelo da REP.

A atividade se desenvolveu onde cada aluno realizou as atividades nos diferentes momentos, ficando evidente a compreensão deles na resolução dos problemas propostos e, com a reflexão sobre as soluções encontradas, foram se apropriando dos conceitos. A participação dos alunos nas atividades surpreendeu as $A B,(2015)$ como demonstrado no depoimento da acadêmica bolsista $B$ no relatório apresentado às coordenadoras do projeto/PIBID/Matemática/UNESC, "a oficina foi a meu ver produtiva, atingimos nosso objetivo e fomos surpreendidos pelo interesse e desenvoltura dos alunos."Em todo o desenvolvimento das atividades foi possível perceber a adequação da proposição didática para prática de sala de aula, pois à medida que cada aluno fazia as atividades ficou evidente a sua compreensão acerca da resolução dos problemas em estudo. E, com a reflexão sobre as soluções encontradas, os conceitos se consolidavam.

As etapas exigiram empenho das acadêmicas bolsistas, mas que contribuiram para aprendizagem tanto dos alunos da escola, quantopara elas, conforme relatado no depoimento da acadêmica bolsista A, 2015: 
"auxiliar os alunos na realização das tarefas propostas despertou em mim, ainda mais, a vontade de ser professora, de lecionar, de passar ao próximo meus conhecimentos e receber o mesmo deles. Dentre os quase 30 alunos participantes, notou-se o desinteresse de alguns, porém a vontade e esforço dos demais foi superior e fez com que levássemos a oficina até o fim".

O depoimento da acadêmica confirma que o objetivo PIBID - que é o de oportunizar as acadêmicas bolsistas situações de aprendizagem e experiências relativas ao processo de qualificação da sua formação para vivencia docente em sala de aula foi alcançado. Por outro lado, pode ser observado que os alunos auxiliados pelas $A B$ realizaram as tarefascom êxito, pois a acadêmica A, (2015) conclui o seu depoimento em relação a atividade desenvolvida argumentando, que

\begin{abstract}
"na reta final da oficina, terminamos a apresentação do slide, propondo aos alunos que desenvolvessem uma relação entre os sólidos de Platão. Por ser uma escola com um índice de aprendizado baixo, não esperávamos que eles conseguissem. Porém para nossa surpresa conseguiram. Isso nos mostra que julgar a turma por uma ideia preestabelecida é errado. Surpreendemo-nos muito com a turma em que a oficina foi aplicada, os alunos foram dedicados e atenciosos, nos mostraram que énecessário vontade e interesse de ensinar e também em aprender ... Apreender nunca tem um fim, cada dia aprendemos algo novo e no dia em que a oficina foi aplicada, a experiência que adquiri, me fez sentir mais confiante para seguir na área da educação".
\end{abstract}

E, também a acadêmica bolsista B, (2015) apresentou suas considerações

A oficina contribuiu para a minha formação como docente, pois foi uma oportunidade de vivenciar o cotidiano escolar e da sala de aula. Serviu como processo de reflexão da prática docente, com possibilidades de traçar perspectivas que enriquecerão o conhecimento tanto no contexto social, cultural e profissional.

Os alunos foram muito participativos, tendo papel ativo na dinâmica da oficina, fazendo perguntas coerentes que mostravam que estavam em um processo de raciocino lógico, e que este raciocínio os levaria a deduzir a fórmula de Euler, principal objetivo da oficina. É na sala de aula, atuando que eu percebi a responsabilidade enquanto formador de opinião e postura.

Os depoimentos das acadêmicas bolsistas do PIBID demonstramos seus sentimentos em relação às atividades desenvolvidas no projeto e estes sentimentos são rotinas a cada atividade proposta e aplicada por eles na escola. Desenvolvemos experiências ricas de significado para formação docente dos acadêmicos bolsistas e ao mesmo tempo, damos subsídios para o docente da escola pública repensar e reciclar a sua prática. Toda semana o grupo se reúne na UNESC e planeja as atividades a serem desenvolvidas na semana seguinte. E esta proposição foiuma 


\section{CRIAR EDUCAČ̃̃̃O}

Revista do Programa de Pós-Graduação em Educação - UNESC

das elaborações e aplicações de proposições didáticas que estudando o que existe na literatura, inferimos numa nova proposição para aplicação em sala de aula.

\section{Conclusão}

Neste trabalho, considera-se que o objetivo foi alcançado $e$ as expectativas superadas, pois os alunos se mostraram participativos, interessados e conseguiram construir o modelo da REP, se apropriando dos conceitos referentes à geometria espacial, por meio da MM. Por outro lado, a inserção dos acadêmicos bolsistas na escola pública é um dos objetivos originais do PIBID e visa promover uma maior integração da universidade com ensino básico e, com este trabalho, foi oportunizado a eles situações de aprendizagem e experiências relativas ao processo de qualificação da sua formação para vivencia docente em sala de aula, previstas também no projeto PIBID.

Os acadêmicos do subprojeto do PIBID/Matemática desenvolvem atividades na UNESC - com orientação das professoras/UNESC coordenadoras do subprojeto - e na escola pública de Educação Básica - sob orientação da professora supervisora (professora da disciplina de Matemática na escola)- toda semana. Então, os acadêmicos bolsistas estão sempre estudando as referências bibliográficas e assistindo e acompanhando as atividades na escola. O subprojeto da matemática atua em três escolas da Educação Básica e o que se apresenta neste trabalho é o resultado de uma destas proposições.

O subprojeto PIBID/Matemática/UNESC, está na escola pública desde 2012. E como pode ser observado, os cursos de Licenciatura e principalmente a Educação ganha com o PIBID nas escolas em termos de formação docente de qualidade e de melhoria da qualidade de ensino e aprendizagem na Educação Básica.

\section{ReferênciasBibiográficas}




\section{CRIAR EDUCAÇÃOO \\ Revista do Programa de Pós-Graduação em Educação - UNESC}

ALMEIDA, L. M. W.; BRITO, D. S. (2005).Atividades de modelagem matemática: que sentido os alunos podem Ihe atribuir?Ciência \& Educação, v. 11, n. 3, p. 483-498, 2005.

ALMEIDA, L.W. de; SILVA, K.P. da; VERTUAN, R.E. Modelagem matemática na educação básica. São Paulo: Contexto, 2012.

ANDRADE, F. C. Uma proposta lúdica ao ensino de geometria espacial no Ensino Médio.Dissertação (Mestrado em Matemática) - Pós-Graduação em Matemática, Universidade Federal do Estado do Rio de Janeiro, Rio de Janeiro, 2014.

MACEDO, J. C. A Modelagem Matemática como estratégia de ensino e aprendizagem de geometria no $8^{\circ}$ ano do ensino fundamental. Dissertação (Mestrado em Matemática) - Pós-Graduação Mestrado Profissional em Matemática,Universidade Federal da Grande Dourados, Mato Grosso do Sul, 2013.

MIALICH, F. R. Poliedros e Teorema de Euler. Dissertação (Mestrado em Matemática) - Pós-Graduação em Matemática Profissional em RedeNacional, Universidade Estadual Paulista, São Paulo, 2013.

TARDIF, Maurice. LESSARD, Claude. O trabalho docente: elementos para uma teoria dadocência como profissão de interações humanas. Rio de Janeiro: Vozes, 2011.

Apoio: PIBID/CAPES e GPEMAHC/UNESC 